\title{
An Innovative Model of Culturally Tailored Health Promotion Groups for Cambodian Survivors of Torture
}

\author{
Sarah Y. Berkson, MD*, Svang Tor*, Richard Mollica, MD, MAR*, James Lavelle, \\ LCSW*, Carol Cosenza, MSW*
}

\begin{abstract}
Cambodians living in the U.S.A. suffer from depression, posttraumatic stress disorder (PTSD), and chronic medical disease at rates far in excess of national averages. The Harvard Program in Refugee Trauma's Cambodian Health Promotion Program seeks to address this burden of disease by offering them culturally tailored health education in a group setting.

A health professional and a bicultural health educator co-facilitated a five-session health promotion group for Cambodian survivors of torture from 2007 to 2011. The program covered five major topics from Western and Cambodian worldviews. They included the meaning of health promotion, nutrition, exercise, stress management and sleep hygiene, and health practitioner-patient communication. The bicultural worker administered Pre and Post semi-structured Health Promotion Questionnaires. The data presented here are the results from 126 participants.

Changes between the Pre and Post health promotion groups demonstrated significant improvements in health status, lifestyle activities, sleep, and depression. Participants revealed greater confidence in communicat-
\end{abstract}

\footnotetext{
*) Harvard Program in Refugee Trauma, Massachusetts General Hospital, Boston, MA 02114, U.S.A.
}

Correspondence to: rmollica@partners.org ing with their primary health care practitioner.

Culturally tailored Cambodian health promotion education administered in a small group setting may improve health and mental health behaviors.

Culturally tailored health promotion education in a small group setting may promote healing in survivors of torture. It is an intervention worthy of further research and development.

Key words: Torture survivor; treatment; Cambodian; health literacy; prevention

\section{Background}

Numerous scientific studies reveal that traumatic life experiences are associated with serious psychiatric and medical problems in mainstream populations. ${ }^{1-4}$ For example, a study of adult health insurance carriers found a strong graded relationship between the breadth of exposure to abuse or household dysfunction during childhood and risk for alcohol and drug abuse, depression, and suicide attempt, as well as heart disease, lung disease, liver disease, cancer, and skeletal fractures. $^{5}$

Increased health risks have likewise been associated with communities that have experienced acts of extreme violence, such as torture. For example, Holocaust survivors have been found to be at increased risk of depression and anxiety disorders, cancer, and 
osteoporosis. ${ }^{6-8}$ They are also at increased risk for cardiometabolic disease, which includes the diseases of hypertension, diabetes, high cholesterol, atherosclerotic heart disease, and vascular dementia. ${ }^{8}$

Like Holocaust survivors, Cambodian survivors of torture have survived extreme violence and suffer from high levels of psychiatric illness. Marshall et al.'s community survey of Cambodians who have resettled in California, conducted between 2003 and 2005, found: "99\% of individuals reported near-death due to starvation, $96 \%$ reported forced labor (like animal or slave), $90 \%$ reported having a family member or friend murdered, and 54\% reported having been tortured." They also found high rates of past-year PTSD (62\%) and major depression (51\%). ${ }^{9}$ Eighty-nine percent of the Cambodians in this study rated their health as either fair or poor. This rate was approximately twice that found in a demographically matched Asian American and Pacific Islanders (AAPI) sample, and more than four times higher than that found in the general California population. ${ }^{10}$ Poor self-rated health is of serious concern, because it has been shown to be a more robust predictor of mortality than physicianassessed health. ${ }^{11}$ Cambodians also reported significantly worse physical functioning than the demographically matched AAPI sample and the general California adult population. ${ }^{10}$

Further research has shown that Cambodians in the US who develop these diseases suffer from higher rates of complications than other Americans. In Lowell, Massachusetts, Cambodian-born adults aged 45 years or older had higher death rates from stroke (15.9\%) and diabetes (13.4\%) compared with all Massachusetts adults in this age group (i.e., $6.5 \%$ for stroke, and $2.5 \%$ for diabetes, respectively). ${ }^{12}$
Other studies of Cambodians also provide growing evidence of the link between trauma and chronic medical and psychiatric symptoms and disorders. Cambodian survivors of the Pol Pot genocide appear to have worse health than Cambodians who did not experience genocide. ${ }^{13}$ A 1990 survey of Cambodian refugees in the Thai refugee camps found a dose-effect relationship between cumulative trauma and the symptoms of PTSD and depression. ${ }^{14}$ Cambodian elders in the United States have been shown to have higher levels of social and physical disability, and greater impairment in activities of daily living, as compared to non-Hispanic Whites, Laotians, and Vietnamese. ${ }^{15}$ Cambodian psychiatric patients are significantly affected by diabetes and hypertension ${ }^{16}$; and somatic symptoms and cultural syndromes ${ }^{17}$. The Cambodians' experience of food deprivation may also contribute to their risk for becoming overweight. ${ }^{18}$ In addition, Cambodians' smaller body habitus puts them at increased risk for diabetes at a body mass index (BMI) of 23 or more, as compared to non-Asians who are at increased risk for diabetes at a BMI of 25 or more. ${ }^{19}$

The earliest Cambodian health education program in the U.S. was a program for women and children in San Diego, California from 1992 - 1994. A case study on this program highlighted the complex cultural factors in Cambodian health, but did not report on the effectiveness of their program. ${ }^{20}$

\section{The Cambodian Health Promotion Program}

The Harvard Program in Refugee Trauma (HPRT) has been caring for survivors of torture since it began as the Indochinese Psychiatry Clinic in 1981. Its clinical work over the past 31 years has focused on caring 
for Southeast Asians-mostly Cambodians. As this population aged, HPRT recognized the increasing burden of chronic medical disease in their patients. In 2000, HPRT responded by initiating the Cambodian Health Promotion Program (CHPP). As described in Healing Invisible Wounds, the CHPP began in a community center in Lowell, Massachusetts as a ten-class course in a small group setting covering a broad range of medical and trauma-related topics. ${ }^{21}$ In 2007, when HPRT moved the CHPP to a primary care center in Lynn, Massachusetts, they limited the program to five sessions so that the course could be offered more times every year and reach more people. Our paper describes the curriculum and results from the CHPP in its current five-session group format.

\section{Methods}

\section{Educational philosophy of the CHPP}

A multidisciplinary team at HPRT designed and implemented the CHPP consistent with the model offered by the Office of Refugee Resettlement ${ }^{22}$ and the Cambodian Elders Council of Lowell ${ }^{23}$. The CHPP team at HPRT included a psychiatrist; a social worker; a Cambodian community health worker; a Cambodian mental health counselor; and a medical student working as a research fellow.

The team designed the process and content of the CHPP based upon an expanded definition of the World Health Organization definition of health ${ }^{24}$ to include self-healing practices learned from the scientific literature and clinical experience. ${ }^{21}$ Health is seen as "a dynamic, active process of maintaining a personal and social state of balance and well-being." Patients are the key agents in promoting their own healing. The group process is well suited to helping participants regain this sense of power over their own health. With skillful group facilitation, group members address their feelings of powerlessness and make constructive changes. ${ }^{25}$ The group process also reduces shame and isolation. ${ }^{25}$ Small groups (about seven to nine participants) provide the ideal intimacy and focused discussion for providing this social support.

Throughout the health promotion groups (HPGs), the CHPP team adapts the teaching technique to the Cambodian audience. Each session is co-facilitated by an American mental health practitioner and a Cambodian community health worker. The co-facilitators integrate Khmer health concepts with evidence-based biomedicine and encourage participants to take an informed and integrated approach to their health. Since the Cambodians' cultural pride has been wounded by the genocide of the Khmer Rouge era, honoring their cultural traditions is a particularly important way to counteract this humiliation.

Not only the HPGs' curriculum, but also their philosophy and process, speak to Cambodian values. A review of multidisciplinary literature on Southeast Asian refugees identified kinship solidarity and the search for equilibrium as two key cultural themes to use in designing health promotion strategies. ${ }^{26}$ The CHPP's group process and philosophy of health as a state of balance speak to these cultural values.

The lesson plans were designed to keep educational messages simple and few, and to allow time for interpretation and discussion. The facilitators found that it could take four times as long to interpret the teaching points into Khmer and discuss them as it would to lecture about the topics in English. The co-facilitators and the participants give concrete examples to illustrate the teaching points. Khmer language educational resources, such as handouts and videos, are also 
used. The co-facilitators prefer illustrated handouts to those with only text because many participants are illiterate in both English and Khmer. The HPG co-facilitators are increasingly using humorous props to make the lessons more accessible, memorable and fun. Indeed, laughter itself can aid in the healing of physical and mental disorders by stimulating positive physiological and immune responses. ${ }^{27}$

\section{Curriculum}

The content of the curriculum centers on five key health behaviors: nutrition, physical activity, stress management, sleep hygiene, and health care practitioner-patient communication.

Session 1 introduces the five-session course by addressing the question: What is health promotion? It introduces the concepts of health promotion and disease prevention by discussing risk and protective factors for specific illnesses. The co-facilitators establish rapport by inviting the participants' perspectives and encouraging discussion. They express appreciation, knowledge, and respect for Khmer healing traditions and cultural history. They set expectations for the course by explaining the structure of the course, its expected benefits and what they expect of the participants. The co-facilitators work to create a nonjudgmental atmosphere where participants can feel comfortable asking questions and sharing what they have learned from their own experiences.

Session 2 teaches basic principles of nutrition and their connection to disease prevention. These guidelines are explained within the context of Cambodian cuisine. For example, when teaching about healthy sources of protein, the co-facilitators acknowledge fish as a healthy feature of traditional Cambodian diet. Likewise, when teaching about sodium reduction for blood pressure control, they recommend limiting the consumption of those traditional Cambodian foods that are high in sodium, such as prahok (a salted fish paste). They accommodate the participants' low literacy by giving them a nutritional guide with pictures of healthy and unhealthy foods.

In session 3, the co-facilitators give guidelines on physical activity, explain its benefits for mental and physical health, and lead exercises together. They recommend aerobic exercise, strength training, and stretching. They recommend consulting health care professionals to help design the right exercise regime for each individual. This recommendation is particularly important for this population, because chronic pain is common among survivors of torture. Many patients require evaluation and treatment by a physical therapist. Finally, the co-facilitators demonstrate the accessibility and fun of exercise by doing low impact exercises together.

In session 4, the group discusses stress, depression and sleep. The co-facilitators teach about the stress response and its connection with chronic disease. They discuss stress reduction techniques and lead the practice of a relaxation response exercise together in class. They normalize how stress is a universal experience and depression is common among survivors of the Pol Pot regime. Mental health is discussed using both Cambodian and Western conceptions. For example, depression is discussed using the Khmer terms pibaak chet and pruoy chet. Pruoy chet is the deep sadness inside a person with extreme suffering that leads the person to withdraw from the world. The sadness is noticeable to others as the person is obviously upset. Pibaak chet is emotional suffering due to misfortune. Usually the emotional distress is not visible to others. ${ }^{28}$ Since poor sleep is a common complaint in 
this population, this session includes some basic guidelines for sleep hygiene. For all of these problems, the co-facilitators recommend both self-management and seeking professional help when that is not enough.

In session 5, patients are encouraged to take an active role in relationship to their health care team. The co-facilitators acknowledge the traditional deference to the authority of the doctor in Cambodian culture and encourage a more collaborative approach. They recommend that patients prepare for their doctors' visits and ask for explanations of anything they do not understand. The co-facilitators end the course by congratulating the participants and giving them certificates of completion.

A more detailed description of the curriculum is available upon request to HPRT.

The procedures were in accordance with the ethical standards of the institutional review boards (IRBs) of Massachusetts General Hospital and Albert Einstein College of Medicine; and with the Helsinki Declaration of 1975, as revised in 1983.

\section{Participants}

The study's 126 participants were recruited as a convenience sample of Cambodians via health care referrals and, to a lesser extent, by community health worker recruitment in the local community. The health care referrals recruited patients from behavioral health and primary care. Recruitment sites in the local community included the Cambodian Buddhist temple and Cambodian grocery stores.

Eligibility criteria included being a primary or secondary Cambodian survivor of torture. All participants had been screened using HPRT's intake instrument that assesses the torture experience of all HPRT patients. This intake instrument includes the trauma/torture events of the Harvard Trauma Questionnaire (HTQ) ${ }^{29}$. Only those patients who are torture survivors are eligible for treatment in HPRT's clinic. Victimization under the Khmer Rouge regime (also known as the Pol Pot genocide) between 1975 and 1979 qualifies as torture according to the US definition of torture in Title 18:

(1) "torture" means an act committed by a person acting under the color of law specifically intended to inflict severe physical or mental pain or suffering (other than pain or suffering incidental to lawful sanctions) upon another person within his custody or physical control;

(2) "severe mental pain or suffering" means the prolonged mental harm caused by or resulting from-

(A) the intentional infliction or threatened infliction of severe physical pain or suffering;

(B) the administration or application, or threatened administration or application, of mind-altering substances or other procedures calculated to disrupt profoundly the senses or the personality;

(C) the threat of imminent death; or

(D) the threat that another person will imminently be subjected to death, severe physical pain or suffering, or the administration or application of mindaltering substances or other procedures calculated to disrupt profoundly the senses or personality... ${ }^{30}$

In addition, the CHPP participants had to be over age 18 and had to have a willingness to participate in the program. Both men and women were eligible to participate. The participants were enrolled and participated from 2007 to 2011. The target enrollment for each group was eight participants.

Participants received no monetary 
compensation for their participation. They were served healthy snacks when attending the course. Upon completion of at least four out of five classes, they received complimentary passes to the localYMCA. While the program itself did not provide transportation for participants, it did connect them with existing free transport services that were available in the community.

\section{Measurement}

\section{Instruments}

A Pre and Post Health Promotion Questionnaire (HPQ) was developed by HPRT, translated into Khmer and administered in a semi-structured interview by the HPRT Cambodian community health worker. The Pre and Post HPQ consists of the following elements.

Depression symptoms were assessed using the 15 depression items from the Cambodian version of the Hopkins Symptom Checklist (HSCL). The HSCL has been found to reliably measure depression symptoms in highly traumatized patients. ${ }^{31-34}$ Each depression symptom is rated as (1) Not at all, (2) A little, (3) Quite a bit, or (4) Extremely. The depression score is calculated by adding up all responses and dividing by the number of items answered. A patient whose depression score is equal to or greater than 1.75 is considered "checklist positive," that is, presumptively demonstrating major depression.

The items of the HPQ on self-perception of health, energy, bodily pain, and social functioning were adapted from the Short Form - 36 (SF-36), a commonly used English-language health survey. The SF-36 survey is a validated questionnaire designed for use in clinical practice and research, health policy evaluations, and general populations surveys. It measures physical health, mental health, social functioning, vitality, and general health perceptions. A large study has supported the use of the SF-36 survey across diverse populations. ${ }^{35}$

For the three items on self-perception of health, energy, and bodily pain, the HPQ maintains the SF-36's five-point scale with one indicating a low rating of the variable in question and five indicating a high rating of that variable. However, the HPQ uses a different scale for social functioning than the SF-36. The original SF-36 item on social functioning asks, "During the past four weeks, how much of the time has your physical health or emotional problems interfered with your social activities (like visiting friends, relatives, etc.)?" and provides a five-point scale for responses ranging from (1) all of the time to (5) none of the time. Our item on social functioning asks, "How many days out of the past week were you totally unable to work or carry out your normal activities because of your health?" Then the participant responds with an answer ranging from 0 to 7 "days out of role". So, in the HPQ, a lower number response for this item indicates higher social functioning.

The remaining items were newly written for the HPQ. Several assessed health behaviors in terms of their duration or frequency. The items on exercise/activity level and relaxation/meditation asked how many minutes per week they engaged in these activities. Sleep was assessed by asking how many hours they sleep per night, with the possible responses being: (1) Less than 4, (2) 4-5, (3) 6-8, and (4) More than 8. Nightmares were assessed in terms of their frequency: (1) daily, (2) several times a week, (3) several times a month, or (4) several times a year. Please note that here a higher number response indicates a reduced frequency of nightmares.

The HPQ, in addition, included four confidence questions: 
1. How confident are you that your health can improve?

2. How confident are you in understanding the causes of your illnesses?

3. How confident are you that you can explain your health problems to your doctor?

4. How confident are you that your doctor can understand you?

The possible responses were (1) Not

Confident, (2) A Little Confident, (3)

Somewhat Confident, and (4) Extremely

Confident.

\section{Analyses}

Analyses were done using the Statistical Package for the Social Sciences (SPSS).

T-tests and one-way ANOVA tests were used to measure differences between the Pre and Post evaluation scores by age groups and gender.

\section{Results}

The demographic background of the HPGs is shown in Table 1. As recorded in their medical records at the community health center, the patients were uneducated, came from rural areas of Cambodia, and resettled in the United States in the 1980s.

This study reveals significant improvement in depressive symptoms, healthy lifestyle behaviors, and confidence in accessing the health care system experienced by the Cambodian survivors of torture who participated in our health promotion groups (HPGs). Table 2 shows the significance of percentage change between the Pre and Post HPG experience. There was a marked reduction in depressive symptoms from $52.8 \%$ of participants who were checklist positive for depression to $44.0 \%$. The portion rating their health status in the lowest category as "poor" dropped from $20.0 \%$ to $7.2 \%$. In the Post data, $80.8 \%$ were exercising at least 120 minutes per week, with only $1.6 \%$ stating that they did not exercise at all. Participants also spent more time in relaxation using meditation. Table 2 also reveals dramatic improvement in sleep and reduced nightmares. Most significantly, after the HPG only $2.4 \%$ of participants felt their health could not improve; none felt their doctor could not understand them; and none felt that they were unable to explain their problems to their doctor.

Table 2 presents the results using mean scores for each HPQ item. All 15 items on the HSCL depression scale revealed significant improvement. All other HPQ items changed significantly for the better except for relaxation per week (in minutes) and the presence of nightmares.

Figures 1 and 2 graphically illustrate the changes in mean score for all HPQ items. Figure 1 reveals dramatic improvement in days out of social role along with "confident understanding causes of illness," and "confident health can improve." Figure 2 demonstrates that, among the 15 depression items of the HSCL, "feeling worthless" and "difficulty sleeping" revealed the greatest improvement. "Feeling blue," "feeling hopeless," and "feeling lonely" form a significant cluster of symptoms that also significantly improved. "Worry" which had the highest pre-test severity of all the symptoms also improved. All other HSCL items also shifted significantly to the left, demonstrating improvement.

The changes between the Pre and Post HPQ results, in summary, demonstrate the following:

1. Improved sense of overall well-being. Participants reported improved health, increased energy, decreased impairment from pain, and increased social functioning.

2. Increased minutes of exercise per week.

3. Improved sleep. Participants reported less 
difficulty sleeping, increased hours of sleep per night, and decreased frequency of recurring nightmares.

4. Improved confidence in health care utilization skills. Participants reported increased confidence that their health can improve; that they understand the causes of their illnesses; that they can explain their health problems to their doctors; and that their doctors can understand them.

5. Improved mood. Participants reported decreased severity of all the depression symptoms on the HSCL.

\section{Discussion}

The results of our study suggest that a brief intervention may improve confidence, knowledge, mood, health behaviors and overall sense of well-being in Cambodian survivors of torture. Participants seemed to gain benefit from the HPGs, despite their generally low level of formal educational attainment. Few participants began with any knowledge of Western concepts of health and healthy lifestyle practices. They had much to gain from simply learning these basic concepts in the HPGs. Improvements may not only be due to gaining knowledge but to gaining a greater sense of confidence in their medical care and a sense of social connectedness from having a shared group experience. Indeed the social experience of the group may be partially responsible for the significant reductions in feelings of "worthlessness" and "feeling trapped." When participants can listen to and be heard by peers who share their struggles, they may feel more validated and accepted, leading to greater feelings of self-worth. Likewise, the social experience may help liberate them from feelings of social isolation. Cultural stereotypes may make one expect that Cambodians would not want to disclose personal health problems in a group setting, but our results suggest that groups are a culturally effective format for Cambodian health promotion.

While the overall HSCL score for depression dropped under the checklist positive score of 1.75 , item by item symptoms all improved including the most severe, "worry," "low energy," and "difficulty sleeping”. This graphic display reveals that clinicians should be sensitive not only to diagnosis but also to the individual items of emotional distress characterizing depression. "Worry," for example, was the most severe presenting symptom of depression. (See Figure 2.) The prominence of "worry" is consistent with past descriptions of common symptom profiles in Cambodian survivors of torture seeking care. Mollica et al's 1984 study of Cambodian psychiatry outpatients at the Indochinese Psychiatry Clinic in Massachusetts found similar results on the HSCL-25. ${ }^{36}$ This study was conducted within several years of the subjects' traumatic experiences under the Khmer Rouge and in refugee camps. The initial Mollica et al. study also had a similar item-by-item graphic analysis of the HSCL symptoms of depression.

Participants on the pretest before the HPG experience reported limited confidence in their ability to communicate with their doctors. To interpret this finding, consider the fact that most participants were patients at a healthcare center with a Cambodian physician and Cambodian nursing staff. This access to Cambodian healthcare staff may have made patients' confidence in their health communications higher than they would be in a care setting without Khmerspeaking staff. Despite this linguistic and cultural common ground, a gap in mutual understanding still remained. While participants on average were initially "somewhat confident" in their ability to communicate with their doctors, they were not "extremely 
confident" in this ability. The HPG experience appeared to help the participants reduce communication barriers with their doctors, as well as helped the patients better understand and apply healthy lifestyle behaviors in their own lives.

Overall improvement was seen in all items for all participants combined. However, only for "confidence" items were there significant differences in the degree to which different demographic groups improved.

Younger participants (under age 50), at baseline, had more confidence in their ability to explain their health problems to the doctor than the older participants, and so did not reveal great gains in this skill. Older men did not attain as much confidence as women that their doctor could understand them. However, there was no difference between younger men and younger women on this item.

This study suggests that culturally tailored Cambodian health education, and HPGs in particular, can improve health and health behaviors in this population. Our pilot study is consistent with the Racial and Ethnic Approaches to Community Health (REACH) project, a Centers for Disease Control and Prevention (CDC) program to eliminate racial and ethnic disparities in health. REACH projects in Seattle and King County, Washington using educational classes and support groups have revealed increased physical activity and healthier eating, and increased self-efficacy in managing diabetes in Cambodian and other ethnic groups. ${ }^{37}$ Another REACH project in the Cambodian community in Lowell, Massachusetts providing culturally tailored health education in order to promote healthy behaviors showed that smoking prevalence decreased in this Cambodian community at a greater rate than nationwide over the same period of time.$^{38}$ More than $50 \%$ of the project's educational workshop and peer support group attendees reported behavioral changes (e.g., limiting salt and/or sugar intake) as a result of attending the group. ${ }^{23}$ The importance of using health education in small group settings is emerging as a major clinical intervention for patients with chronic diseases such as diabetes and obesity 25,39

\section{Limitations}

This study was conducted as a pilot to evaluate clinical outcomes and as such it suffers from methodological weaknesses. It lacks a control group. It has selection bias, resulting from who was invited to the course, chose to come, and stayed. Since many of the participants were patients recruited by their behavioral health care providers, our sample may report more severe psychiatric symptoms, and then would not be representative of the general local Cambodian population. Also, since the HPGs took place in the early afternoon, the sample was likely biased towards those who are not working. While the overall curriculum topics were constant throughout the study period, the exact way they were taught in the program varied over time. The Cambodian health educator who taught the course was the same person who administered the instruments, so this dual role introduces another possible source of bias. Our data show correlations from which causation cannot be inferred. Like other Cambodian health education programs, CHPP also offered screening and referral to appropriate services. The CHPP also encouraged participants to use allopathic and traditional healing methods they found helpful; and to discuss these practices with their health care team. As such, the effects of education versus those of increased health care utilization (allopathic or traditional) cannot be disaggregated. Finally, there was a lack of long-term follow-up data to see if 
these improvements were sustained. Substantial resources would have been needed to address the methodological weaknesses of this unfunded study.

Key unanswered questions are: are the benefits of the Cambodian Health Promotion Program sustained over time? Are these groups more efficacious than conventional care? Do different characteristics such as level of education and types/severity of trauma/torture events affect ability to profit from these groups? What is necessary to maintain these benefits over time? Addressing these questions would require a control group study with a larger and more diverse sample size. Long-term follow-up - for example, by repeated evaluations at one and five years after program participation would also be valuable.

Despite these limitations, this pilot study suggests that HPGs are a promising intervention worthy of further implementation and investigation. Future program development could seek to optimize the content, format, and pedagogy of the program. Future research could systematically assess the clinical effectiveness of HPGs.

\section{Conclusion}

Our study suggests that improvements in health, health behaviors, sleep, confidence, and depression symptoms can occur through participation in our Cambodian Health Promotion Program. Our data reveals the potential benefits of culturally tailored health education in a small group setting for Cambodian survivors of torture. Even though this is a pilot study, these findings offer a pathway for torture survivors and their health practitioners to improve the health and medical care of survivors. Our study suggests that culturally tailored health education in a small group setting may promote healing in survivors of torture. The key elements of this model of health education are (1) identification of topic areas based on needs assessment; (2) integration of the survivors' culture into an evidence-based curriculum; (3) small group process; and (4) systematic evaluation. We suggest that it is feasible to incorporate health promotion groups for survivors of torture into a comprehensive program of community-based health care.

\section{Acknowledgements}

We want to thank our wonderful participants for their enthusiasm and courage. We want to thank Lynn Community Health Center for hosting the program and for their help with recruitment for the program. Sarah Y. Berkson would also like to thank Dr. Albert S. Kuperman and the Albert Einstein College of Medicine for supporting her fellowship at the Harvard Program in Refugee Trauma.

For more information about the Cambodian Health Promotion Program, please contact the Harvard Program in Refugee Trauma by emailing stor@partners.org or calling 617-876-7879. 
Table 1: Demographic characteristics of Health Promotion Group (HPG) participants ( $n=126)$

$\begin{array}{ll}\text { Demographics } & \text { Percen } \\ \text { Age } & \\ 50 \text { and younger } & 22.4 \% \\ 51-60 & 46.4 \% \\ 61+ & 31.2 \%\end{array}$

Gender

Female $\quad 64 \%$

Male $\quad 36 \%$

Table 2: Health Promotion Questionnaire (HPQ) responses in terms of percentages of participants $(n=126)$

\section{Health Promotion Questionnaire Items}

Health

Health rated as "poor"»

Energy rated "none" to "a little"

Bodily pain rated as "moderately" to "extremely"^

Social functioning:

Reporting 3 or more days out of role*

Health behaviors

Exercise of less than 120 minutes per week ${ }^{\star}$

Did not exercise at all ${ }^{\star}$

Relaxation of less than 60 minutes per week ${ }^{\star}$

Did not relax at all*

Sleep

Less than 4 hours per night ${ }^{\star}$

Daily nightmares *

Confidence items (4-point scale)

Not confident that health can improve*

Not confident understanding causes of illnesses ${ }^{\star}$

Not confident can explain health problems to doctor ${ }^{\star}$

Not confident doctor can understand you ${ }^{\star}$

Depression score greater than or equal to $1.75^{\star}$

$\begin{array}{lll}\text { Pre } & \text { Post } & \text { p } \\ \text { HPQ } & \text { HPQ }\end{array}$

$20.0 \% \quad 7.2 \% \quad .001$

$39.2 \% \quad 17.6 \% \quad .000$

$42.4 \% \quad 29.6 \% \quad .011$

$36.8 \% \quad 26.4 \% \quad .042$

$44.0 \% \quad 19.2 \% \quad .000$

$12.8 \% \quad 1.6 \% \quad .001$

$61.6 \% \quad 48.0 \% \quad .004$

$51.2 \% \quad 36.0 \% \quad .002$

$25.6 \% \quad 10.4 \% \quad .000$

$13.6 \% \quad 3.3 \% \quad .011$

$21.6 \% \quad 2.4 \% \quad .000$

$19.2 \% \quad 2.4 \% \quad .000$

$7.2 \% \quad 0 \% \quad .002$

$\begin{array}{lll}4.0 \% & 0 \% & .025\end{array}$

$52.8 \% \quad 44.0 \% \quad .034$ 
Table 2

Health Promotion Questionnaire items

$\begin{array}{cccc}\begin{array}{c}\text { Mean } \\ \text { Pre }\end{array} & \begin{array}{c}\text { Mean } \\ \text { Post }\end{array} & \begin{array}{c}\text { Delta } \\ \text { (mean }\end{array} & \text { P } \\ \text { score } & \text { score } & \text { change) } & \end{array}$

Health

Health rating (5-point scale) ${ }^{\star}$

1.95

2.39

$-0.44$

0.000

Energy rating (5-point scale) ${ }^{\star}$

2.88

3.29

$-0.41$

0.000

Bodily pain rating (5-point scale $)^{\star}$

2.33

2.00

0.33

0.001

Social functioning (days out of role) ${ }^{\star}$

2.40

1.51

0.89

0.019

Health behaviors

Exercise per week (minutes) ${ }^{\star}$

Relaxation per week (minutes)

$\begin{array}{rrrr}159.63 & 195.6 & -35.97 & 0.004 \\ 64.76 & 81.85 & -17.09 & 0.150\end{array}$

Sleep

Average hours of sleep per night

(4-point scale) ${ }^{\star}$

1.98

2.34

$-0.36$

0.000

Presence of recurring nightmares

0.77

0.73

0.04

0.258

Infrequency of recurring nightmares

(4-point scale) ${ }^{\star}$

2.24

2.59

$-0.35$

0.001

Confidence items (4-point scale)

Confident health can improve ${ }^{\star}$

Confident understanding causes of illnesses ${ }^{\star}$

2.26

2.91

$-0.65$

0.000

2.34

2.96

$-0.62$

0.000

Confident can explain health problems to

doctor $^{\star}$

3.00

3.48

$-0.48$

0.000

Confident doctor can understand you ${ }^{\star}$

3.18

3.54

$-0.36$

0.000

Depression symptoms (4-point scale)

Low energy ${ }^{\star}$

2.33

2.05

0.28

0.000

Self blame*

2.11

1.85

0.26

0.002

Crying easily*

1.70

1.43

0.27

0.000

Loss of sexual interest ${ }^{\star}$

1.98

1.80

0.18

0.005

Poor appetite*

1.86

1.57

0.29

0.000

Difficulty sleeping ${ }^{\star}$

2.22

1.81

0.41

0.000

Feeling hopeless ${ }^{\star}$

2.10

1.80

0.30

0.000

Feeling blue*

2.18

1.84

0.34

0.000

Feeling lonely ${ }^{\star}$

2.04

1.73

0.31

0.000

Suicidal thoughts*

1.09

1.03

0.06

0.020

Feeling trapped ${ }^{\star}$

1.98

1.62

0.36

0.000

Worry ${ }^{\star}$

2.43

2.17

0.26

0.000

No interest in things ${ }^{\star}$

1.81

1.56

0.25

0.000

Feeling everything is an effort ${ }^{\star}$

2.09

1.80

0.29

0.000

Feeling worthless ${ }^{\star}$

1.97

1.60

0.37

0.000

Depression score*

1.99

1.71

0.28

0.000

${ }^{\star}$ Difference between Pre and Post scores was statistically significant $(\mathrm{p}<0.05)$.

Note: The direction of change for all items indicates improvement. 
Figures 1 \& 2: Changes in mean scores from Pre to Post Health Promotion Questionnaires

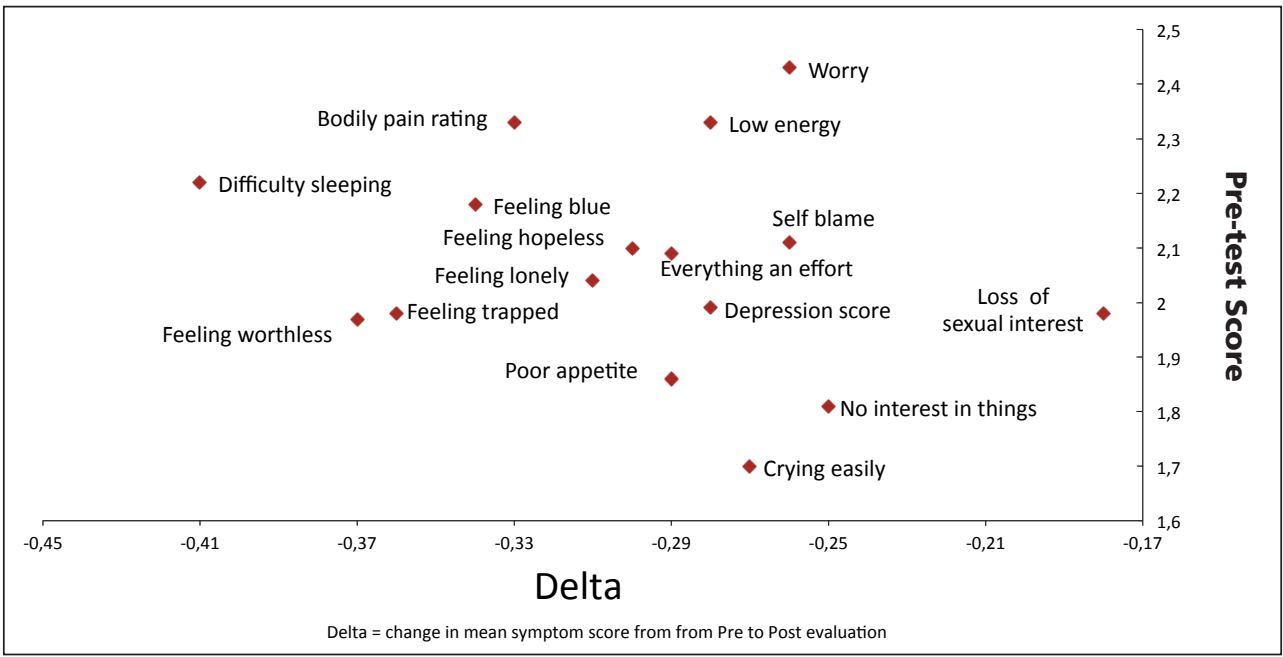

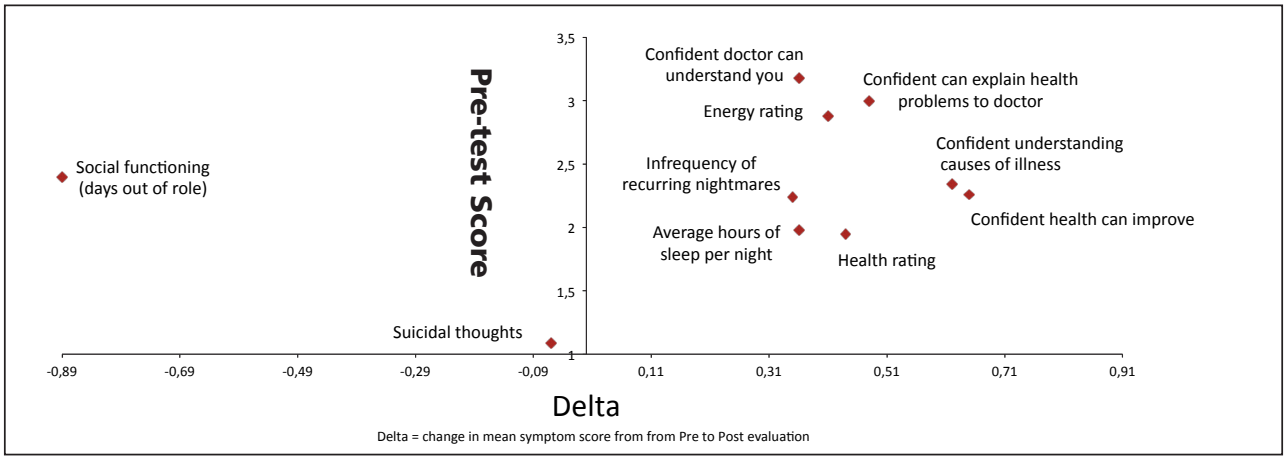




\section{References}

1. Holmes TH, Rahe RH. The Social Readjustment Rating Scale. Journal of psychosomatic research. 1967 Aug;11(2):213-8. PubMed PMID: 6059863. Epub 1967/08/01. eng.

2. Edwards VJ, Holden GW, Felitti VJ, Anda RF. Relationship between multiple forms of childhood maltreatment and adult mental health in community respondents: results from the adverse childhood experiences study. The American journal of psychiatry. 2003 Aug;160(8):1453-60. PubMed PMID: 12900308.

3. Sareen J, Cox BJ, Stein MB, Afifi TO, Fleet C, Asmundson GJ. Physical and mental comorbidity, disability, and suicidal behavior associated with posttraumatic stress disorder in a large community sample. Psychosomatic medicine. 2007 Apr;69(3):242-8. PubMed PMID: 17401056.

4. Sledjeski EM, Speisman B, Dierker LC. Does number of lifetime traumas explain the relationship between PTSD and chronic medical conditions? Answers from the National Comorbidity Survey-Replication (NCS-R). Journal of behavioral medicine. 2008 Aug;31(4):341-9. PubMed PMID: 18553129. Pubmed Central PMCID: 2659854.

5. Felitti VJ, Anda RF, Nordenberg D, Williamson DF, Spitz AM, Edwards V, et al. Relationship of childhood abuse and household dysfunction to many of the leading causes of death in adults. The Adverse Childhood Experiences (ACE) Study. American journal of preventive medicine. 1998 May;14(4):245-58. PubMed PMID: 9635069. Epub 1998/06/23. eng.

6. Shmotkin D, Barilan YM. Expressions of Holocaust experience and their relationship to mental symptoms and physical morbidity among Holocaust survivor patients. Journal of behavioral medicine. 2002 Apr;25(2):115-34. PubMed PMID: 11977434.

7. Keinan-Boker L, Vin-Raviv N, Liphshitz I, Linn S, Barchana M. Cancer incidence in Israeli Jewish survivors of World War II. Journal of the National Cancer Institute. 2009 Nov 4;101(21):1489-500. PubMed PMID: 19861305.

8. Paratz ED, Katz B. Ageing Holocaust survivors in Australia. The Medical journal of Australia. 2011 Feb 21;194(4):194-7. PubMed PMID: 21401461.

9. Marshall GN, Schell TL, Elliott MN, Berthold SM, Chun CA. Mental health of Cambodian refugees 2 decades after resettlement in the United States. JAMA : the journal of the American Medical Association. 2005 Aug 3;294(5):571-9. PubMed PMID: 16077051. Epub 2005/08/04. eng.
10. Wong EC, Marshall GN, Schell TL, Elliott MN, Babey SH, Hambarsoomians K. The unusually poor physical health status of Cambodian refugees two decades after resettlement. Journal of immigrant and minority health / Center for Minority Public Health. 2011 Oct;13(5):876-82. PubMed PMID: 20878473.

11. Mossey JM, Shapiro E. Self-rated health: a predictor of mortality among the elderly. American journal of public health. 1982 Aug;72(8):800-8. PubMed PMID: 7091475. Pubmed Central PMCID: 1650365.

12. Centers for Disease Control and Prevention (U.S.). The power to reduce health disparities: voices from REACH communities. Atlanta, Ga.: U.S. Dept. of Health and Human Services, Centers for Disease Control and Prevention; 2007. 85 p. p.

13. Mollica RF, Brooks R, Tor S, Lopes-Cardozo B, Silove $\mathrm{D}$. The enduring mental health impact of mass violence: A community comparison study of Cambodian civilians living in Cambodia and Thailand. International Journal of Social Psychiatry. Epub 2013 Feb 7. PubMedPMID:23396287.

14. Mollica RF, McInnes K, Poole C, Tor S. Doseeffect relationships of trauma to symptoms of depression and post-traumatic stress disorder among Cambodian survivors of mass violence. The British journal of psychiatry: the journal of mental science. 1998 Dec;173:482-8. PubMed PMID: 9926076.

15. Yang MS, Burr JA, Mutchler JE. The prevalence of sensory deficits, functional limitations, and disability among older Southeast Asians in the United States. Journal of aging and health. 2012 Oct;24(7):1252-74. PubMed PMID: 22948086.

16. Kinzie JD, Riley C, McFarland B, Hayes M, Boehnlein J, Leung P, et al. High prevalence rates of diabetes and hypertension among refugee psychiatric patients. The Journal of nervous and mental disease. 2008 Feb;196(2):108-12. PubMed PMID: 18277218. Epub 2008/02/16. eng.

17. Hinton DE, Hinton AL, Eng KT, Choung S. PTSD and key somatic complaints and cultural syndromes among rural Cambodians: the results of a needs assessment survey. Medical anthropology quarterly. 2012 Sep;26(3):383-407. PubMed PMID: 23259349.

18. Peterman JN, Wilde PE, Liang S, Bermudez OI, Silka L, Rogers BL. Relationship between past food deprivation and current dietary practices and weight status among Cambodian refugee women in Lowell, MA. American journal of public health. 2010 Oct;100(10):1930-7. PubMed PMID: 20724691. Epub 2010/08/21. eng.

19. Southeast Asian Subcommittee of the Asian 
American/Pacific Islander Work Group National Diabetes Education Program. U. S. Department of Health and Human Services' National Diabetes Education Program; 2006. 11-8]. Available from: http://www.ndep.nih.gov/media/SilentTrauma.pdf.

20. Palinkas LA, Pickwell SM, Warnock F. Community-based health promotion for Cambodian refugees: a case study. Journal of immigrant health. 1999 Jan;1(1):53-5. PubMed PMID: 16228715 Epub 2005/10/18. eng.

21. Mollica RF. Healing invisible wounds: paths to hope and recovery in a violent world. Nashville: Vanderbilt University Press; 2009. p. 188-213.

22. Family Support Administration Office of Refugee Resettlement. Promoting Mental Health Services of Refugees: A handbook on model practices Washington, DC: U.S. Department of Health and Human Services; 1991. III.10-III.4] Available from: http://aspe.hhs.gov/pic/reports/ acf/3928.pdf.

23. Grigg-Saito D, Och S, Liang S, Toof R, Silka L. Building on the strengths of a Cambodian refugee community through community-based outreach. Health promotion practice. 2008 Oct;9(4):415-25. PubMed PMID: 17494947. Epub 2007/05/15. eng.

24. WHO definition of Health. Preamble to the Constitution of the World Health Organization as adopted by the International Health Conference, New York, 19-22 June, 1946; signed on 22 July 1946 by the representatives of 61 States (Official Records of the World Health Organization, no. 2, p. 100) and entered into force on 7 April 1948.

25. Eisenstat S, Siegel AL, Carlson K, Ulman K. Putting Group Visits Into Practice: A Practical Overview to Preparation, Implementation, and Maintenance of Group Visits at Massachusetts General Hospital. Boston, Massachusetts: Women's Health Associates The John D. Stoeckle Center for Primary Care Innovation Massachusetts General Hospital; 2012. p. 6-7.

26 . Frye BA. Use of cultural themes in promoting health among Southeast Asian refugees. American journal of health promotion : AJHP. 1995 Mar-Apr;9(4):269-80. PubMed PMID: 10150730. Epub 1995/02/07. eng.

27. Martin R. Sense of Humor. In: S. J. Lopez CRS, editor. Positive Psychological Assessment: A Handbook of Models and Measures. Washington, DC: American Psychological Association; 2003. p. 313-26.

28. Lavelle J, Tor S, Mollica RF, Allden K, Potts L. Harvard Guide to Khmer Mental Health: Presi- dent and Fellows of Harvard College; 1996.

29. Mollica RF, Caspi-Yavin Y, Bollini P, Truong T, Tor S, Lavelle J. The Harvard Trauma Questionnaire: Validating a cross-cultural instrument for measuring torture, trauma, and posttraumatic stress disorder in Indochinese refugees. The Journal of nervous and mental disease. 1992 Feb;180(2):111-6.

30. 18 USC \2340 - Definitions 1994. Available from: http://www.law.cornell.edu/uscode/ text $/ 18 / 2340$

31. Mollica R, Wyshak G, Coelho R, Lavelle J. The Southeast Asian psychiatry patient: a treatment outcome study. Washington, DC: U.S. Office of Refugee Resettlement; 1985.

32. Derogatis LR, Lipman RS, Rickels K, Uhlenhuth $\mathrm{EH}$, Covi L. The Hopkins Symptom Checklist (HSCL): a self-report symptom inventory. Behavioral science. 1974 Jan;19(1):1-15. PubMed PMID: 4808738. Epub 1974/01/01. eng.

33. Mollica RF, Wyshak G, de Marneffe D, Khuon F, Lavelle J. Indochinese versions of the Hopkins Symptom Checklist-25: a screening instrument for the psychiatric care of refugees. The American journal of psychiatry. 1987 Apr;144(4):497-500. PubMed PMID: 3565621. Epub 1987/04/01. eng.

34. Silove D, Manicavasagar V, Mollica R, Thai M, Khiek D, Lavelle J, et al. Screening for depression and PTSD in a Cambodian population unaffected by war: comparing the Hopkins Symptom Checklist and Harvard Trauma Questionnaire with the structured clinical interview. The Journal of nervous and mental disease. 2007 Feb;195(2):152-7. PubMed PMID: 17299303. Epub 2007/02/15. eng.

35. McHorney CA, Ware JE, Jr., Lu JF, Sherbourne CD. The MOS 36-item Short-Form Health Survey (SF-36): III. Tests of data quality, scaling assumptions, and reliability across diverse patient groups. Medical care. 1994 Jan;32(1):40-66. PubMed PMID: 8277801.

36. Mollica RF, Wyshak G, Lavelle J, Truong T, Tor $\mathrm{S}$, Yang T. Assessing symptom change in Southeast Asian refugee survivors of mass violence and torture. The American journal of psychiatry. 1990 Jan;147(1):83-8. PubMed PMID: 2293793. Epub 1990/01/01. eng.

37. Garvin CC, Cheadle A, Chrisman N, Chen R, Brunson E. A community-based approach to diabetes control in multiple cultural groups. Ethnicity \& disease. 2004 Summer;14(3 Suppl 1):S83-92. PubMed PMID: 15682776. Epub 2005/02/03. eng.

38. Liao Y, Tsoh JY, Chen R, Foo MA, Garvin CC, Grigg-Saito D, et al. Decreases in smoking preva- 
lence in Asian communities served by the Racial and Ethnic Approaches to Community Health (REACH) project. American journal of public health. 2010 May;100(5):853-60. PubMed PMID: 20299646. Epub 2010/03/20. eng.

39. Trento M, Passera P, Borgo E, Tomalino M, Bajardi M, Cavallo F, et al. A 5-year randomized controlled study of learning, problem solving ability, and quality of life modifications in people with type 2 diabetes managed by group care.

Diabetes care. 2004 Mar;27(3):670-5. PubMed PMID: 14988283. Epub 2004/02/28. eng. 